\title{
PENGENDALIAN PENGELOLAAN OBAT \\ DI INSTALASI FARMASI \\ SUATU RUMAH SAKIT SWASTA KOTA BANDUNG
}

\author{
Ida Lisni ${ }^{1}$, Herman Samosir ${ }^{2}$, Ester Mandalas ${ }^{3}$ \\ 1,2 Universitas Bhakti Kencana \\ ${ }^{3}$ Rumah Sakit Advent Bandung \\ Email korespondensi: ida.lisni@bku.ac.id
}

\begin{abstract}
ABSTRAK
Pengelolaan obat meliputi proses kegiatan perencanaan, pengadaan, penyimpanan, distribusi dan pengendalian yang diselengarakan oleh suatu farmasi rumah sakit agar ketersediaan obat dapat terjamin dalam jumlah yang cukup, dalam pelaksanaannya membutuhkan dana yang cukup besar. Penelitian dilakukan untuk mengevaluasi pengelolaan obat di farmasi rumah sakit swasta di kota Bandung dengan menggunakan standar indikator yang telah ditetapkan. Penelitian menggunakan metode observasional non eksperimental yang bersifat retrospektif. Data yang dikumpulkan berupa data perencanaan dan pengadaan obat, pemakaian obat, kartu stok obat, laporan stok opname. Hasil penelitian didapatkan bahwa pencapaian perencanaan obat $107,53 \%$, frekuensi pembelian untuk kategori rendah sebesar 34,70\%, kategori sedang 41,08\% dan kategori tinggi $24,22 \%$, persentase obat kadaluarsa $0,085 \%$ dan persentase stok mati $3,81 \%$.
\end{abstract}

Kata kunci : Evaluasi, pengelolaan obat, instalasi farmasi 


\title{
DRUG MANAGEMENT CONTROL IN THE PHARMACY OF A PRIVATE HOSPITAL BANDUNG CITY
}

\begin{abstract}
Drug management is a series of planning, procurement, storage, distribution, and control activities carried out by a hospital pharmacy so that drug availability can be guaranteed in sufficient quantities, in its implementation requires a large number of funds. The study was conducted to evaluate drug management in private hospital pharmacies in the city of Bandung using predetermined standard indicators. This study used a retrospective non-experimental observational method. The data collected is in the form of planning data and drug procurement, drug use, drug stock cards, stocktaking reports. The results showed that the achievement of drug planning (107.53\%), the frequency of purchase for the low category (34.70\%), the medium category was $41.08 \%$ and the high category (24.22\%), expired drugs (0.085\%) and the dead stock $(3.81 \%)$.
\end{abstract}

Keywords : Evaluation, Drug Management, Hospital Pharmacy

\section{PENDAHULUAN}

Konsep kesatuan dari upaya kesehatan dijadikan pedoman dan pegangan bagi semua fasilitas kesehatan di Indonesia, termasuk rumah sakit (Satibi, 2014). Tujuan dari upaya kesehatan agar terpelihara dan peningkatan Kesehatan. Tempat penyelenggara upaya kesehatan disebut sarana kesehatan. Rumah sakit termasuk salah satu sarana kesehatan yang menyelenggarkan upaya Kesehatan. Rumah sakit beserta organisasi yang terdapat di dalamnya harus dikelola dengan sebaik-baiknya, agar dapat memberikan pelayanan kesehatan kepada masyarakat dengan baik, sehingga tujuan terciptanya derajat kesehatan yang optimal dapat tercapai.
Saat ini, rumah sakit memiliki peran sebagai organisasi pelayanan kesehatan yang sedang memasuki lingkungan global yang kompetitif dan akan terus berubah sehingga membutuhkan pengelolaan yang tepat. Seperti halnya industri, rumah sakit dituntut harus mampu bersaing agar dapat bertahan dalam persaingan global (Arnita, 2014).

Pekerjaan kefarmasian adalah pembuatan termasuk pengendalian mutu sediaan farmasi, pengamanan, pengadaan, penyimpanan, pendistribusian atau penyaluran obat, pengelolaan obat, pelayanan obat atas resep dokter, pelayanan informasi obat, serta pengembangan obat, bahan obat dan obat tradisional (Pemerintah RI, 2009)

https://doi.org/10.33759/jrki.v3i2.134 
Instalasai Farmasi memiliki kewenangan dalam proses pengadaan obat/sediaan farmasi, dengan cara beli langsung maupun melaksanakan produksi sendiri dalam skala kecil sesuai kebutuhan (Siregar, 2004).

Obat dan sediaan farmasi lainnya yang dikelola dalam jumlah banyak, membutuhkan biaya yang besar dan biaya yang ditimbulkan akan meningkat jika pengelolaan persediaan tidak tepat. Dengan demikian rumah sakit sangat penting melakukan pengendalian persediaan agar dapat terciptanya suatu efisiensi dalam penggunaan modal. Persediaan obat yang efektif adalah jika dapat memenuhi keperluan dari unit pelayanan kesehatan yang menjadi cakupannya. Jika terjadi kesalahan dalam pengelolaannya akan menimbulkan dampak seperti pemborosan, kekurangan obat, tidak tersalurnya obat, obat kadaluarsa dan rusak, dan lain sebagainya. Suatu unit pelayanan yang sering mengalami kesalahan dalam setiap rangkaian proses pengeloaan, maka semakin tidak efektif (Quick, 2012).

Apoteker bertanggungjawab dalam pengendalian pengelolaan perbekalan farmasi. Tanggungjawab ini diterapkan dan dilaksanakan terhadap jenis dan jumlah persediaan serta penggunaan sediaan farmasi, alat kesehatan, dan bahan medis habis pakai. Pengendalian penggunaan sediaan farmasi, alat kesehatan, dan bahan medis habis pakai dapat dilaksanakan oleh farmasi rumah sakit harus bersama dengan Komite/Tim Farmasi dan Terapi di Rumah Sakit (Kementrian Kesehatan RI, 2016)

Berdasarkan uraian tersebut di atas, dilakukan penelitian mengenai Pengendalian Pengelolaan Obat di Farmasi pada suatu Rumah Sakit Swasta Kota Bandung untuk mengevaluasi pengelolaan obat di farmasi rumah sakit swasta di kota Bandung berdasarkan standar indikator yang telah ditetapkan.

\section{METODE PENELITIAN}

Penelitian merupakan penelitian observasional non eksperimental. Data yang diambil adalah data retrospektif, kemudian dianalisis secara kuantitatif dan kualitatif serta data di sajikan secara deskriptif. Deskriptif adalah suatu penelitian yang digunakan untuk membuat penelitian terhadap suatu kondisi dan penyelenggaraan suatu program kemudian hasilnya digunakan untuk menyusun perbaikan program tersebut (Notoatmodjo, 2012)

\section{Rancangan Penelitian}

1. Pengambilan data

Pengambilan data dilakukan secara retrospektif dari bulan Oktober sampai Desember 2018 .

2. Sumber data

Data diperoleh dari data perencanaan dan pembelian obat, data pemakaian obat, kartu stok obat, daftar obat kadaluarsa dan rusak serta data obat stok mati selama periode tiga bulan (Oktober-Desember 2018).

3. Pengolahan data

Dari data tersebut dilakukan analisis terhadap ketepatan perencanaan dan pengadaan obat, frekuensi pembelian 
obat, persentase nilai obat kadaluarsa dan rusak serta persentase nilai stok mati. Data yang dikumpulkan kemudian dibandingkan hasilnya dengan indikator pengelolaan obat di rumah sakit.

4. Penarikan Kesimpulan

Dari hasil pengolahan data, ditarik kesimpulan yaitu ketepatan

\section{HASIL DAN PEMBAHASAN}

\section{Gambaran Umum Sistem \\ Pengelolaan Obat}

Pengelolaan obat adalah bagian dari luang lingkup dari pelayanan farmasi rumah sakit, harus dapat menciptakan aspek keamanan, efektif dan ekonomis dalam penggunaannya. Pengelolaan obat diselenggarakan dengan baik supaya terjamin ketersediaan dan pelayanan obat yang rasional, efektif serta efisien. Farmasi rumah sakit sebagai unit pelaksana teknis, melakukan perencanaan dan pengadaan obat sesuai dengan kebutuhan dan anggaran, baik itu dalam pemilihan jenis, jumlah, dan harga obat. Perencanaan obat diselenggarkan dengan metode konsumsi yang diperoleh dari data pemakaian obat bulan sebelumnya berdasarkan laporan pembelian, penerimaan obat dan perencanaan dan pengadaan obat, frekuensi pembelian obat, persentase nilai obat yang memasuki masa kadaluarsa dan rusak, dan persentase nilai stok mati, kemudian dibandingkan dengan standar pelayanan kefarmasian di rumah sakit.

pengeluaran bulanan setelah dilakukan perencanaan kemudian dilakukan proses pengadaan obat. Untuk pengadaan obat dilakukan dengan cara metode pembelian langsung yaitu pihak instalasi farmasi secara langsung melakukan pengadaan obat (setelah barang habis atau stok berkurang ) kepada pihak Pedagang Besar Farmasi (Departemen Kesehatan RI, 2008)

Waktu pengadaan obat di farmasi rumah sakit dalam penelitian ini dilakukan pada hari Senin sampai Jumat, namun kuantitas pengadaan diutamakan pada hari Senin dan Kamis. Hal ini dilakukan untuk dapat memantau ketersediaan dan sisa obat yang ada.

\section{Pencapaian Perencanaan}

Hasil dari pencapaian perencanaan pada penelitian ini didapat dengan menggunakan rumus sebagai berikut :

$$
\mathrm{X}=\mathrm{A} / \mathrm{B} \times 100 \%
$$

Dimana $A=$ Jumlah item obat dalam kenyataan pembelian $\mathrm{B}=$ Jumlah item obat dalam perencanaan

Tabel I. Pencapaian Perencanaan Obat terhadap Pembelian Perbulan

\begin{tabular}{lccccc}
\hline Bulan & $\begin{array}{c}\text { Perencanaan } \\
\text { (item) }\end{array}$ & $\begin{array}{c}\text { Pengadaan } \\
\text { (item) }\end{array}$ & $\begin{array}{c}\text { Selisih } \\
\text { (item) }\end{array}$ & Persentase & $\begin{array}{c}\text { Persentase } \\
\text { penyimpangan }\end{array}$ \\
\hline Oktober & 1479 & 1604 & 125 & $107.79 \%$ & $7.79 \%$ \\
November & 1503 & 1596 & 93 & $105.83 \%$ & $5.83 \%$ \\
Desember & 1503 & 1651 & 148 & $108.96 \%$ & $8.96 \%$
\end{tabular}




\begin{tabular}{ccccc}
4485 & 4851 & 366 & 322.58 & 22.58 \\
Total Rata-Rata & & 122 & 107.53 & $7.53 \%$ \\
\hline
\end{tabular}

Proses perencanaan obat di Instalasi Farmasi, dimulai dengan pengumpulan data penggunaan obat bulan sebelumnya dan dilihat stok yang ada. Dari hasil penelitian diketahui metode yang digunakan adalah metode konsumsi, alasan menggunakan metode ini karena dinilai lebih mudah dalam pelaksanaannya ((DepKes RI, 2008). Ketersediaan dana yang cukup akan berpengaruh pada pelayanan. Karena dengan ketersediaan dana yang memadai maka pengadaan dapat diselenggarakan sesuai perencanaan (Mahdiyani, U dkk, 2018)

Dapat dilihat pada Tabel I, bahwa jumlah obat yang direncanakan oleh rumah sakit selama periode OktoberDesember 2018 adalah sebesar 4485 dan jumlah pemakaiannya adalah 4851 , sehingga didapat hasil perhitungan ketepatan perencanaan obat sebesar $107,53 \%$. Hasil dari penelitian perencanaan di farmasi rumah sakit tersebut belum memenuhi indikator yang ditetapkan dalam penelitian Ismedsyah dan Rahayu,S (2019) yaitu indikator ketepatan perencanaan adalah 100\%. Ketidaktepatan ini disebabkan adanya perencanaan yang dilakukan tidak sesuai dengan pemakaian obat. Kondisi ini dapat terjadi karena adanya perubahan penyakit tertentu yang memerlukan penanganan segera, sehingga dilakukan pembelian baru, dapat juga disebabkan karena kekosongan obat oleh distributor tertentu sehingga dilakukan perencanaan ulang atau pola peresepan dokter yang berubah juga dapat membuat ketidaktepatan dalam perencanaan. Salah satu contoh terjadi pada Actifed $60 \mathrm{ml}$ syrup yang tidak ada dalam perencanaan namun dilakukan pembelian karena adanya permintaan untuk obat tersebut. Ketepatan perencanaan diharapkan dapat menghindari kekosongan obat ataupun stok mati. Keberhasilan dari ketepatan perencanaan bergantung pada metode yang digunakan dalam melakukan pengadaan obat, sehingga dapat memperkecil biaya atau kerugian rumah sakit. Perencanaan yang dilakukan berdasarkan penggunaan obat bulan sebelumnya, sehingga dapat diketahui jumlah penggunaan obat, dan ketika melakukan perencanaan, petugas juga melihat stok yang masih ada untuk menghindari penumpukan.

Hasil penelitian Ihsan dkk (2015) diketahui adanya kesenjangan antara perencanaan dan realisasi mencapai 9,15 \%, dan dari hasil penelitian Ismedsyah dan Rahayu (2019) diperoleh penyimpangan perencanaan $4,7 \%$. Semakin besar persentase penyimpangan perencanaan, maka kualitas pelayanan farmasi semakin berkurang.

\section{Frekuensi Pengadaan tiap Item Obat}

Pengadaan obat yang dilakukan di farmasi rumah sakit dilakukan dengan pembelian langsung. Frekuensi pengadaan obat dalam 3 bulan diklasifikasikan berdasarkan frekuensi pengadaan menjadi 3 (Pudjaningsih, 1996), yaitu frekuensi rendah (< 3), 
sedang (3-6), dan tinggi (> 6). Volume pembelian obat yang besar menyebabkan frekuensi pembeliannya rendah dan volume pembelian obat yang kecil maka frekuensi dalam pembeliannya tinggi. Besarnya jumlah item obat dengan frekuensi sedang dan tinggi menunjukkan kemampuan instalasi farmasi rumah sakit dalam merespons perubahan kebutuhan obat dalam jumlah sesuai dengan kebutuhan obat saat itu. Pengadaan obat yang berulang juga menggambarkan bahwa yang tersedia di farmasi rumah sakit merupakan obat dengan perputaran cepat.

Tabel II. Frekuensi Pengadaan Item Obat Oktober-Desember 2018

\begin{tabular}{lccc}
\hline $\begin{array}{c}\text { Frekuensi } \\
\text { Pengadaan }\end{array}$ & $\begin{array}{c}\text { Jumlah } \\
\text { Item Obat }\end{array}$ & $\begin{array}{c}\text { Persentase } \\
(\%)\end{array}$ & Status \\
\hline$<3$ & 702 & 34,70 & Rendah \\
$3-6$ & 831 & 41,08 & Sedang \\
$>6$ & 490 & 24,22 & Tinggi \\
\hline Total & 2023 & 100 & \\
\hline
\end{tabular}

Tabel II, terdapat frekuensi pembelian yang rendah sebesar $34,70 \%$ atau ada 702 item obat, hal ini dapat mengakibatkan perputaran obat yang lambat sehingga berpotensi menimbulkan stok mati bahkan dapat mengakibatkan obat kadaluarsa jika kurang dalam pengawasannya

Hasil perhitungan persentase frekuensi pengadaan tiap item obat didapat dari data obat masuk di instalasi farmasi kemudian diamati berapa kali item obat dipesan, dimana didapatkan hasil pengadaan obat untuk frekuensi rendah sebanyak $34,70 \%$ dan untuk frekuensi sedang sebanyak $41,08 \%$ sedangkan untuk frekuensi tinggi sebanyak $24,22 \%$. Dari hasil frekuensi pengadaan obat didapatkan hasil untuk frekuensi sedang dan tinggi sebesar 65,30\%. Tingginya frekuensi pengadaan obat, memiliki arti bahwa perputaran obat dalam rumah sakit berjalan baik dan dapat mencegah persediaan obat yang mengendap. Perlu pengawasan terhadap obat obat dengan frekuensi pembelian yang rendah yang jumlahnya mencapai $34,70 \%$, karena besar kemungkinan obat tersebut adalah obat dengan perputaran yang rendah yang dapat menyebabkan obat dengan stok mati dan dapat menjadi kadaluarsa.

\section{Jumlah Obat Kadaluarsa dan Rusak}

Tujuan dari manajemen pengelolaan perbekalan kefarmasian di rumah sakit adalah menjamin persediaan efektif dan efisien atau tidak terjadi kelebihan dan kekurangan/kekosongan, kerusakan, kadaluwarsa, dan kehilangan (Kementrian Kesehatan, 2016). Pada Tabel III, dapat dilihat jumlah dan nilai (rupiah) dari obat kadaluarsa dan rusak. Hasil perhitungan persentase dari nilai obat kadaluarsa dan rusak, dikumpulkan dari data obat yang ada di farmasi rumah sakit, masih ada obat yang kadaluarsa dan rusak sebesar $0.085 \%$ dengan nilai sebesar Rp.3.316.200. Persentase ini didapat dari nilai total obat yang kadaluarsa dibagi dengan nilai stok opname dikalikan $100 \%$. 
Walaupun penyimpangannya $0.085 \%$, namun ini juga dikatakan belum efisien, karena menyebabkan kerugian pada rumah sakit. Nilai obat kadaluarsa pada penelitian ini lebih rendah dibandingkan terhadap hasil penelitian Permata, D
(2016), yaitu Rp 8.209.726 dan penelitian Ihsan, S (2015) yaitu Rp. $6.591 .654(0,33 \%)$ serta dari hasil penelitian Waluyo,dkk (2015) diperoleh $7,01 \%$

Tabel III. Jumlah dan Nilai Obat Kadaluarsa

\begin{tabular}{lcccc}
\hline Nama obat & $\begin{array}{c}\text { Bentuk } \\
\text { Sediaan }\end{array}$ & Jumlah & $\begin{array}{c}\text { Harga obat } \\
\text { ( Rp.) }\end{array}$ & $\begin{array}{c}\text { Nilai obat } \\
\text { kadaluarsa (Rp.) }\end{array}$ \\
\hline Dalacin 150 & tablet & 90 & 9.985 & 898.650 \\
dynastat & injeksi & 8 & 119.800 & 958.400 \\
hemocain & Salep & 2 & 73.700 & 147.400 \\
ikaphen & Injeksi & 15 & 87.450 & 1.311 .750 \\
\hline Total & & & & 3.316 .200 \\
\hline Nilai stok opname & & & 3.863 .116 .985 \\
\hline
\end{tabular}

Terjadinya obat kadaluarsa dan rusak menunjukkan kurangnya ketepatan perencanaan dan pengamatan penyimpanan obat serta perubahan pola penyakit. Obat rusak dan kadaluarsa dapat terjadi karena kurangnya pengendalian serta pengawasan mutu (Waluyo, dkk, 2015). Adanya persentase obat kadaluarsa disebabkan kurangnya pengawasan dalam tahap penyimpanan yang menyebabkan obat kadaluarsa. Adanya peresepan dokter yang bervariasi, dapat menyebabkan perubahan dalam penggunaan obat sehingga ada obat yang tidak keluar dan tidak digunakan menyebabkan penumpukan dan menjadi kadaluarsa. Untuk mengatasi agar tidak terjadi stok yang kadaluarsa perlu dilakukan evaluasi dalam pelaksanaan penyimpanan dan juga kemampuan serta ketrampilan dari petugas farmasi dalam pemantauan obat-obat yang mendekati waktu kadaluarsa.

\section{Persentase Stok Mati (Dead Stock)}

Adanya stok mati pada persediaan obat di rumah sakit sangat berkaitan dengan proses perencanaan. Perencanaan obat yang baik dapat mencegah terjadinya stok mati. Presentase stok mati didapat dari hitungan perbandingan antara jumlah obat yang tidak ada transaksi dalam jangka waktu 3 bulan terus menerus dengan total jumlah obat yang ada stoknya dikalikan dengan $100 \%$ (Ihsan, S dkk, 2014). Indikator dari stok mati adalah persentase stok mati adalah 0\% (Departemen Kesehatan RI, 2008)

Paraturan Menteri Kesehatan RI No.72 tentang Standar Pelayanan Kefarmasian di Rumah Sakit menyatakan bahwa salah satu cara pengendalian cara untuk pengendalian dalam pengelolaan sediaan farmasi di rumah sakit adalah melakukan evaluasi persediaan yang tidak digunakan dalam waktu tiga bulan berturut-turut (dead stock). 
Pada Tabel IV, dapat dilihat jumlah dan

persentase obat dead stock.

Tabel IV. Persentase Stok Mati

\begin{tabular}{ccc}
\hline $\begin{array}{c}\text { Jumlah item obat }>3 \text { bulan } \\
\text { tidak terpakai }\end{array}$ & $\begin{array}{c}\text { Jumlah item obat } \\
\text { yang ada stoknya }\end{array}$ & $\begin{array}{c}\text { Persentase stok } \\
\text { mati }\end{array}$ \\
\hline 59 & 1548 & $3.81 \%$ \\
\hline
\end{tabular}

Hasil pengamatan yang didapat untuk persentase stok mati, yaitu obat obat yang tidak digunakan atau tidak terdapat transaksi selama 3 bulan sebesar $3.81 \%$. Terdapat 59 item obat stok mati, yaitu obat obat yang tidak ada transaksi dari 1548 jenis obat yang stoknya tersedia. Kerugian rumah sakit akibat dari stok mati adalah perputaran uang yang terhambat, dan berpotensi terhadap kadaluarsa obat bahkan kerusakan obat karena terlalu lama disimpan. Seperti contoh obat Plantacid Forte sebanyak 100 tablet tidak mengalami transaksi selama lebih dari 3 bulan. Kondisi ini dikarenakan dokter tidak meresepkan obat tersebut, melainkan dokter meresepkan obat yang lain dan juga kurang tepatnya perencanaan pengadaan obat. Untuk mengurangi kerugian dapat dilakukan dengan mengembalikan obat tersebut kepada distributor. Apoteker rumah sakit sebaiknya aktif berkomunikasi dan koordinasi dengan dokter melalui Tim Farmasi dan Terapi untuk mengurangi dead stock.

Hasil dari penelitian ini lebih besar jika dibandingkan terhadap penelitian Dyahariesti, N., Yuswantina, R (2019), persentase stok mati adalah $2,7 \%$ dan lebih rendah jika dibandingkan terhadap hasil penelitian Permata, D. 2016 yaitu diperoleh stok mati tahun 2010 dan
2011 sebanyak 12,76\% senilai Rp 45.191.156. Semakin tinggi persentase stok mati maka akan semakin berdampak terhadap pelayanan obat di rumah sakit.

\section{KESIMPULAN}

Kesimpulan dari penelitian ini adalah :

1. Pencapain perencanaan obat terhadap pembelian mencapai nilai $107,53 \%$.

2. Frekuensi pengadaan obat untuk kategori rendah sebesar $34,70 \%$, kategori sedang $41,08 \%$ dan kategori tinggi $24,22 \%$.

3. Terdapat Obat Kadaluarsa dan rusak sebesar $0.085 \%$, dan obat stok mati sebesar $3,81 \%$.

4. Peran aktif apoteker rumah sakit dalam pengendalaian pengelolaaan obat perlu ditingkatkan untuk menjamin persediaan efektif dan efisien.

\section{UCAPAN TERIMAKASIH}

Pada kesempatan ini, peneliti ingin mengucapkan terima kasih kepada berbagai pihak yang telah membantu terwujudnya penelitian ini :

1. Dekan Fakultas Farmasi Universitas Bhakti Kencana

2. Pimpinan Salah Satu Rumah Sakit Swasta di Bandung

https://doi.org/10.33759/jrki.v3i2.134 


\section{DAFTAR PUSTAKA}

Arnita, A. A.2014. Analisis FaktorFaktor Yang Mempengaruhi Obat Stagnant Di Instalasi Farmasi Rumah Sakit. Universitas Hasanuddin Makassar Tahun 2014. Tesis Universitas Hasanuddin Makassar.

Departemen Kesehatan RI, 2008. Jendral Bina Kefarmasian dan Alat Kesehatan, Pedoman Pengelolaan Perbekalan Farmasi Di Rumah Sakit. Departemen Kesehatan RI, Jakarta.

Dyahariesti, N., Yuswantina, R. 2019. Evaluasi Keefektifan Penggelolaan Obat di Rumah Sakit. Media Farmasi Indonesia Vol 14 No 1, hal 1485-1492.

https://mfi.stifar.ac.id/MFI/article/v iew/109/90

Ihsan, S, Amir, S.A., Sahid, M.2015. Evaluasi Pengelolaan Obat di Instalasi Farmasi Rumah Sakit Umum Daerah Kabupaten Muna Tahun 2014. Pharmauho: Jurnal Farmasi, Sains, dan Kesehatan Vol 1 , No 2. http://ojs.uho.ac.id/index.php/phar mauho/article/view/3465/2619.

Ismedsyah \& Rahayu,S. 2019. Ecaluasi Perencanaan Obat dan Perbekalan Farmasi di Depo Pusat Jantung
Terpadu RSUP Haji Adam Malik Medan. Jurnal Surya Medika Volume 4 No.2 hal 41-50. https://doi.org/10.33084/jsm.v4i2.5 $\underline{46}$.

Kementerian Kesehatan RI, 2016. Peraturan Menteri Kesehatan Republik Indonesia Nomor 72 tentang standar pelayanan kefarmasian di Rumah Sakit, Jakarta.

Mahdiyani, U., Wiedyaningsih, C., Endarti, D. 2018. Evaluasi Pengelolaan Obat Tahap Perencanaan dan Pengadaan di RSUD Muntilan Kabupaten Magelang Tahun 2015 -2016. Jurnal Manajemen dan Pelayanan Farmasi Volume 8 No. 1 hal 24-31. https://doi.org/10.22146/jmpf.31883.

Pemerintah RI, 2009. Peraturan Pemerintah No.51 tentang Pekerjaan Kefarmasian, Jakarta.

Permata, D. 2016. Strategi Pengendalian Persediaan Obat Pada Instalasi Farmasi Rumah Sakit Islam Ibnu Sina Bukittinggi. Jurnal Ekonomi STIE Agus Salim Bukittinggi Volume 19 No. 1 (2016) hal $1-14$. https://doi.org/10.47896/je.v19i1

Pudjaningsih. D. 1996. Pengembangan Indikator Efisiensi Pengelolaan Obat di Farmasi Rumah Sakit. Tesis. 
Magister Manajemen Rumah Sakit. Yogyakarta. Universitas Gajah Mada

Quick, D.J., Hume, M.L, Raukin J.R,Laing, RO., and O'Connor, RW.,2012, Managing Drug Supply, Revised and Expanded, Kumarin Press, West Hartford.

Satibi. 2004. Manajemen Obat di rumah sakit, Yogyakarta, Gadjah Mada University Press

Siregar dan Amalia, Lia.2004, Farmasi Rumah Sakit, Teori dan Penerapan,
25 - 49, Penerbit Buku Kedokteran EGC, Jakarta.

Waluyo,YW., Athiyah,U., dan Rochma, TN. 2015. Analisis Faktor yang Mempengaruhi Pengelolaan Obat Publik di Instalasi Farmasi Kabupaten (wilayah Papua Selatan tahun 2014). Jurnal Ilmu Kefarmasian Indonesia Volume 13 tahun 2015 hal 94-101. http://jifi.farmasi.univpancasila.ac.i d/index.php/jifi/article/view/131 